\title{
Alternative Uses of Eddy Current Inspection in Materials Engineering
}

Petr Beneš, Matěj Kotrba, Antonín Kř́ž

Faculty of Mechanical Engineering, University of West Bohemia, Univerzitní 22, 306 14, Plzeň.Czech Republic. E-mail: pbenes@kmm.zcu.cz,mkotrba@students.zcu.cz,kriz@kmm.zcu.cz

There are a large number of special methods for exploring the internal condition of materials on the basis of eddy currents. A major use of this method can be seen in surface engineering, particularly in studying some state quantities of surface integrity. It is also an irreplaceable tool in surface engineering. The reason is that no other affordable method provides information on both the surface and the sub-surface regions, as the latter are difficult to reach by most other inspection methods. It must be noted that the sub-surface region is significant, and dictates, to a large extent, the behaviour of the overlying surface. This article explores a non-traditional application of eddy current inspection. This inspection technique is typically used for detecting discontinuities in material. The study presented here involves a use of this non-destructive testing method for studying work hardening in two metallic materials: EN AW-1090 aluminium alloy, and S235JR-C carbon steel.

Keywords: eddy currents, work hardening

\section{Acknowledgements}

This article was made possible by the funding for the SGS-2015-016 project “Analysis of Surfaces of Structural Details and Tools by Surface Integrity Method, and Impacts on End-Use Properties“.

\section{References}

[1] OLYMPUS. Eddy Current Array Tutorial [online]. [Accessed 1.6.2016]. http://www.olympus-ims.com/en/ ndttutorials/eca/tutorial.

[2] http://www.nde-ed.org/EducationResources/CommunityCollege/EddyCurrents/Introduction. [online]. [Accessed 1.6.2016]

[3] POHL, R., ERHARD, A., MONTAG, H.-J., THOMAS, H.-M., WUSTENBERG (2003). NDT Techniques for Railroad Wheel and Gauge Corner Inspection. In: NDT and E International, Vol. 37, pp. 89 - 94. Elsevier.

[4] HÁJEK, J., Ǩ̌ÍŽ, A., HRDLIČKA, V. (2015). The Heat Treatment of Aluminium Bronzes, Manufacturing Technology. Vol.15, No. 1., pp.35-41.

[5] HÁJEK, J., KŘÍŽ, A., JIRKA, T. (2016). Distortion after Case Hardening of Steels, Manufacturing Technology. Vol.16, No. 4., pp.697-702.

[6] PElletier, E., GRENIER, M., CHAHBAZ, A., BOURGElAS, T. (2006). Array Eddy Current for Fatigue Crack Detection of Aircraft Skin Structures. In: Proceedings of Advances in Signal Processing for Non Destructive Evaluation of Materials, X. Maldague ed., Canada, Quebec city. 